\title{
A New Approach for Supply Chain Risk Management: Mapping SCOR into Bayesian Network
}

\author{
Mahdi Abolghasemi, Vahid Khodakarami, Hamid Tehranifard \\ Bu Ali Sina University (Ismalic Republic of Iran) \\ m.abolghasemi@basu.ac.ir,v.khodakarami@,basu.ac.ir, h.tehranifard@,basu.ac.ir
}

Received: October 2014

Accepted: February 2015

\section{Abstract:}

Purpose: Increase of costs and complexities in organizations beside the increase of uncertainty and risks have led the managers to use the risk management in order to decrease risk taking and deviation from goals. SCRM has a close relationship with supply chain performance. During the years different methods have been used by researchers in order to manage supply chain risk but most of them are either qualitative or quantitative. Supply chain operation reference (SCOR) is a standard model for SCP evaluation which have uncertainty in its metrics. In This paper by combining qualitative and quantitative metrics of SCOR, supply chain performance will be measured by Bayesian Networks.

Design/methodology/approach: First qualitative assessment will be done by recognizing uncertain metrics of SCOR model and then by quantifying them, supply chain performance will be measured by Bayesian Networks (BNs) and supply chain operations reference (SCOR) in which making decision on uncertain variables will be done by predictive and diagnostic capabilities.

Findings: After applying the proposed method in one of the biggest automotive companies in Iran, we identified key factors of supply chain performance based on SCOR model through predictive and diagnostic capability of Bayesian Networks. After sensitivity analysis, we find out that 'Total cost' and its criteria that include costs of labors, warranty, transportation and 
inventory have the widest range and most effect on supply chain performance. So, managers should take their importance into account for decision making. We can make decisions simply by running model in different situations.

Research limitations/implications: A more precise model consisted of numerous factors but it is difficult and sometimes impossible to solve big models, if we insert all of them in a Bayesian model. We have adopted real world characteristics with our software and method abilities. On the other hand, fewer data exist for some of the performance metrics.

Practical implications: Mangers often use simple qualitative metrics for SCRM. However, combining qualitative and quantitative metrics will be more useful. Industries can recognize the important uncertain metrics by predicting supply chain performance and diagnosing possible happenings.

Originality/value: This paper proposed a Bayesian method based on SCOR metrics which has the ability to manage supply chain risks and improve supply chain performance. This is the only presented case study for measuring supply chain performance by SCOR metrics.

Keywords: risk management, performance measurement, SCOR, bayesian networks

\section{Introduction}

Increasing rate of organizations' growth in recent years and their needs to each other has led to activities complication in supply chain. In addition, the supply chain uncertainties cause managers to find a way in order to endure in the competitive world of business. In supply chain which consists of suppliers, manufacturers, transportation, distribution, wholesalers, retailers and customers, all members of the supply chain try to provide customers with timely, reliable and high quality delivery of the right amount of products at low cost. The uncertainty in transportation, costs, packaging and distribution, pricing, after sales services, guaranty and warranty requirements are some examples that can affect the performance of the supply chain. Also exchange and inflation rates are some of external uncertainties that can threat supply chain, however; accurate management of them can improve supply chain performance (SCP) and provide customer's satisfaction. Using SCP metrics should be an early priority for senior managers so that changes will be done in the supply chain based on the customers' needs and demands (Johnson \& Pyke, 2000; MCCREA, 2006).

Significant growth of supply chain risk management (SCRM) was mainly due to the terrorist events of 2001 in America, Katrina hurricane in 2005 and the SARS outbreak in Asia in 2003 (Wagner \& Bode, 2006). The results of study shows the negative effects and potential 
problems in supply chain have caused $31 \%$ reduction in profits due to the lack of proper risk management (Hendricks \& Singhal, 2005). Supply chain managers can manage potential challenges, and prevent the destructive effects, by creating risk departments in organizations and identifying risks.

The supply chain operations reference (SCOR) model, proposed by the supply chain council (SCC), is a standard for SCP evaluation model and provides a unique framework that hat can be used to map, benchmark, and improve supply chain operations.

It has been widely embraced by many modern organizations. The SCOR model enables enterprises to analyze their SCP in a systematic way, to enhance communication among the members in the supply chain, and to design a better supply chain network.

Recent studies provided empirical understanding of SCOR-type performance metrics and their relationship to supply chain inter-firm performance. Gunasekaran, Patel and McGaughey (2004) assessed metrics based on elements of plan, source, make, and deliver as found in Gunasekaran, Patel and Tirtiroglu (2001). The results from their study provided general support for the link between SCP metrics to improve downstream supply chain inter-firm performance and market position. Today's uncertain business environment requires supply chain managers to assess the degree of risk across the whole range of activities in a supply chain and develop suitable strategies to mitigate them. The uncertainty in each of the performance metrics can affect SCP and efficient management of them leads to better performance of supply chain.

We will analyze a system in supply chain using SCOR metrics and assess its efficiency by a new method which is capable to predict performance and also diagnose possible scenarios. BNs are graphical models that show a set of possible variables and their conditional dependencies. It is a decision-making tool that can help mangers to manage risks within different fields. They are useful for measuring risk and also providing predictive and diagnostic information for better mitigating risk. We will incorporate both qualitative and quantitative metrics to present a flexible model.

This paper is organized as follows. In section 2 we will briefly introduce supply chain risk management. Section 3 provides some of studies which carried out in SCRM and SCOR. We will describe our proposed model in details in section 4. The application and validation of the model will be shown through case study scenario analysis in sections 5 and 6 respectively. Finally it ends with conclusion. 


\section{Supply Chain Risk Management}

In today's unstable period, businesses and, more specifically, supply chains becoming increasingly global, the industrial environment is heavily affected by uncertainty, which can potentially turn into unexpected disruptions (McCormack, Wilkerson, Marrow, Darvey Shah \& Yee, 2008).

Supply chain problem is a multidisciplinary problem which has common areas with many issues including marketing, management and economy. The extent of supply chain and uncertainty in lots of its parameters makes it more complicated. Production and delivery time, quality, safety, inventory, transportation and equipment reliability are among variables that can affect the performance of the supply chain.

Risk by Pettit, Fiksel and Croxton (2010) is defined as: Changes in the function of potential output, the probability of their occurrence and amount. Risk management is the process of evaluating all the possibilities and assessment of gains against the potential risks. The System ability to return to its original state or better condition after accident, is another definition of SCRM presented by Christopher and Peck (2004).

Other definitions have been proposed, all of which tracking conceptually one goal. The ultimate goal of the risk management process is protecting the integrity of organization against the unfortunate events and their consequences in order to gain maximum power and ability to make profit as much as possible (Rowbottom, 2004; Van Hoek, 2003). The lack of proper risk management implementation caused losses in many organizations and companies. For instance, both Apple and Ericsson suffered from over 400 and 300 million euros losses respectively, due to the poor risk management (Norrman \& Jansson, 2004).

SCRM is a step by step process. All of the proposed processes are seeking one goal; however they have some differences in implementation stages. Tuncel and Alpan (2010) announced risk identification, risk assessment, risk management and risk monitoring as the four steps of SCRM. Jüttner, Peck and Christopher (2003) have argued that SCRM consists of four key management aspects: assessing the risk sources for the supply chain, defining the supply chain adverse consequences, identifying the risk drivers, and finally mitigating risks for the supply chain.

Supply Chain Council members have reported that less than half of enterprises have established metrics and procedures for assessing and managing supply risks and organizations lack sufficient market intelligence, process, and information systems to effectively predict and mitigate supply chain risks.

As stated by Fox, Barbuceanu and Teigen (2001) the next generation of supply chain management system should be distributed, dynamic, intelligent, integrated, responsive, 
reactive, cooperative, interactive, anytime, complete, reconfigurable, general, adaptable, and backwards compatible.

Christopher, Mena, Khan and Yurt (2011) found that most companies did not have a structured management and mitigation system covering supply chain risk. It is therefore no surprise that risks are considered the main reason why desired performance is not achieved in supply chains (Hendricks, Singhal \& Zhang, 2009).

\section{Overview of Literature}

There are different categories of SCRM in the literature, and each one focuses on a particular approach.

Some focused on different types of risks and their classification from their opinion. According to some researchers, risks are divided into internal or external. Internal risks such as human errors, equipment failures, and materials quality that can be controlled by the organization. External risks including exchange rate changes, legislation and natural events such as earthquakes which cannot be controlled by the organization ( $\mathrm{Wu}$, Blackhurst \& Chidambaram, 2006).

Svensson (2000) divided risks into two main categories: qualitative and quantitative and mentioned to different risks for each of categories. Li and Barnes (2008) addressed this question from market perspective and reviewed supply chain risks from the customers' views. By considering customers' needs, they tried to use suppliers that meet their customers' needs better. Cavinato (2004) analyzed the supply chain risks through physical aspects. He examined the possibility of physical damage to the equipment, such as warehouses and production lines. Also, he analyzed the asset protection mechanisms to present economic and technical recommendations for risk management.

Operational risks and disruption is Tang (2006) classification. Operational risks are referred to the inherent uncertainties such as uncertain customer demand, uncertain supply, and uncertain cost. Disruption risks are referred to the major disruptions caused by natural and man-made disasters such as earthquakes, floods, hurricanes, terrorist attacks, etc., or economic crises such as currency evaluation or strikes.

Logistics, inventory, organizing, competitive, cooperative, morality, credit, cultural, information transfer, information, technology and safety are the another kinds presented by Yan, Xu and Wang (2008). Supply, operational, demand, and security by Manuj and Mentzer (2008) and supply, demand, operational, and security by Christopher and Peck (2004) are other presented points of view. 
The second area goes to various types of modeling for risk management. A large amount of literature describes several modeling techniques that can assist decision makers in supply chain. Modeling has an essential role on problem solving. Pettit et al. (2010) states "the best level of resilience will be achieved only when a balance is maintained between capabilities and vulnerabilities."

Gunasekaran et al. (2004) has implemented a conceptual risk management model for a chemical manufacturing company in America and presented a quantitative approach for risk management. They introduced ten principles as the requirements of risk management in order to evaluate and control risk.

Gunasekaran et al. (2001) has presented an analytical risk model by distributing questionnaires among supply chain risk professionals and managers to quantify risks. The questions were presented in 5 sections: demand risks, supply risks, legal and bureaucracy risks, infrastructural risks, and catastrophic risks.

Rabelo, Eskandari, Shaalan and Helal (2007) combined analytical hierarchical analysis by system dynamics and simulation with discrete event to model services in a global supply chain. In his model, profitability, customer satisfaction, power, responsibility and political strength, were considered as indicators of choosing the best chain.

Deterministic models, stochastic models, hybrid models, and IT-driven models is a modeling classification presented by Min and Zhou (2002). Although his modeling classification is good but it is not comprehensive enough. Graphical models which were ignored in their classification are another types of modeling that were used in this paper too. Graph theory (Wagner \& Neshat, 2010), critical path analysis (Jüttner et al., 2003), causal tree structure (Pai, Kallepalli, Caudill, \& Zhou, 2003) and work-flow diagrams (Adhitya, Srinivasan, \& Karimi, 2009) are some of graphical methods used by different researchers.

Today's uncertain business environment requires supply chain managers to assess the degree of risk across the whole gamut of activities in a supply chain and develop suitable strategies to mitigate them. Some research areas were associated with the risk measurement and risk control strategies.

In Giunipero and Eltantawy (2004) research, risk control and analysis methods are presented by conceptual examining of supply chain risk model. They are believed, to determine the level of risk management in supply chain, we should take production technology, security needs, the suppliers and customers experience into account and the relevant and worthy management should be performed depending on the circumstances of each chain.

Wu and Olson (2008) used simulation and Balanced Score Card (BSC) to manage supply chain risk in a bank. They consider the criteria of BSC (financial, customer, internal process, learning 
and innovation) in each area and set goals for them. Also they offered measuring criterion for each area.

All of the works done in SCRM are seeking one goal, that is, reducing their impact and controlling them. There are many different ways to reduce uncertainties and theirs impact. One approach to mitigating upstream uncertainty is the use of a buffer or safety inventory (Milgate, 2001).

Tang and Tomlin (2008) showed the application and ability of flexibility approach in reducing supply chain risk. They considered supply risks, processes, intellectual property, social and political behavior as supply chain risk classifications. In another division (Chopra \& Sodhi, 2012) considered disruption, delay, systematic risk, forecast, intellectual property risks, operational risk, inventory and capacity as important risk parameters in supply chain.

Yongsheng and Kun (2009) identified the risks caused by own, environment and system qualitatively. In their opinion, by using this classification, supply chain risk can be analyzed better and they will be able to choose the appropriate response to control the risk. Control, avoidance, prevention, and acceptance are their strategies in management.

Hunter, Kasouf, Celuch and Curry (2004) considered the probability and severity as the risk indexes, and proposed strategies according to the situations of them. Supply chain disruptions can have significant impact on a firm's short-term performance as well as long-term negative effects. Mitigation approach includes supply management, demand management, product management and information management as a classification by Tang (2006).

Cirtita and Glaser-Segura (2012) evaluated key performance indicators in downstream supply chain and chose SCOR model. They considered time delivery, responsibility, flexibility, supply chain costs and asset management efficiency as their variables and identified important variables using correlation matrix. Their article is one of the few papers that examine the performance of the downstream chain but the impact of variables on each other has not been considered.

Shi (2004) divided the supply chain risk into core business and non-core business risks. In main part, he proposed valuable risks (quality, quantity, price, time, services, and complexity) and operational risks (systematic, political, process and people). In non-systemic part he identified the repetitive risks that usually exist in organizations by some variables like markets, exchange rates, inflation, debt and liabilities. Supply chain design, supplier selection, sales contracts design, production design, collaboration and outsourcing were Shi's solutions for risk management strategies.

SCOR is a consensus model. It was developed and continues to evolve with the direct input of industry leaders who manage global supply chains and use it daily to analyze and improve the 
performance of their organizations. It features an intentionally broad scope and definitions that can be adapted to the specific supply chain requirements of any industry or application. SCOR identifies five core SCP attributes: Reliability, Responsiveness, Flexibility, Costs, and Asset Management.

The SCOR model is now integrated with processes that identify potential risk elements throughout the supply chain, define metrics to assess the potential impact of these risk elements and enable companies to control impact and mitigate service disruptions (McCormack et al., 2008).

Gunasekaran et al. (2004) presented a framework for supply chain performance measurement. Different metrics of supply chain performance measurement provided for order, supply, production level, delivery, customer service and supply chain costs factors. They performed an empirical study in British companies and developed a framework for supply chain performance. (Arzu Akyuz \& Erman Ekran, 2010) reviewed different methods of supply chain performance measurement. They classified the papers based on their topics and methodologies. Also they mentioned to the importance of SCOR and BSC in supply chain performance measurement. All parts of the chain are linked together somehow and their performance can affect each other. Mutual risk identification and assessment can be seen as tools for creating the risk profile of the network on the basis of the partners' risk profiles (Hallikas, Karvonen, Pulkkinen, Virolainen \& Tuominen, 2004). It is necessary to identify risks that may be unimportant for an individual partner but will affect significantly the whole supply chain or other partners' operational capability. Identification and implementation of mutual means for risk reduction help to discover risk management actions that may be too expensive to be implemented by a single partner, but cheap enough to be implemented by collaboration (Faisal, Banwet, \& Shankar, 2007).

Many risks in downstream, interior and upstream areas are common. The extent and complexity of the chain relations make it almost impossible to review all aspects of this issue. Also performance metrics are uncertain and they can vary due to different reasons. On the other hand, despite the critical role of quantification, most of the studies in supply chain risks are qualitative and quantification had been less noted by researchers. However, it seems that combining qualitative and quantitative metrics will be more efficient and close to the real world problems.

The SCOR contains supply chain risk management metrics and it has imported among the performance metrics. As we mentioned in section 2, the SCOR model is now integrated with processes that identify potential risk elements throughout the supply chain. We are going to select the appropriate metrics for measuring our SCP and use them in BN. 
We focused on above mentioned properties and present a new model to fill these gaps. The presented model is able to help us in decision making by analyzing predictive and diagnostic events. Furthermore, it is both graphical and quantified model and easy to understand.

BNs are useful method for modeling risk. The BN model proposed in this paper is an aid to supply chain managers in order to take better decisions in uncertain environment. BNs are able to predict and diagnose events as well as combining quantitative and qualitative metrics. We have special metrics for each of SCOR attributes that shows the SCP. Since these metrics have uncertainty in there nature, we can model them by a risk management tool.

\section{Proposed Model}

Lockamy and McCormack (2004) found specific relationship between the plan, source, make, and deliver elements of SCOR and inter-firm performance. Lambert and Pohlen (2001) stated that their experience with firms has shown no support for the view that performance metrics are used for inter-firm coordination along the supply chain. They stated that the used metrics are for internal use only.

In this section we have defined a new methodology using BNs for modeling SCP. First, we presented BNs briefly and then we modeled it by SCOR metrics. The proposed methodology provides supply chain mangers with the opportunity to mitigate supply chain risks by creating a Bayesian model based on SCOR metrics for selecting the best alternative to mitigate risks.

\subsection{Bayesian Networks}

BNs are graphical models that show a set of possible variables and their conditional dependencies by directed acyclic graph. BN nodes represent variables. These variables can be observable values, hidden variables or unknown parameters. Edges of BN represent the dependencies. Each node has a probability function which consists of initial probability (for nodes without parents) or conditional probabilities related to different combinations of parent nodes.

Bayes' theorem expresses the relation between the dependent variables. Bayes theorem uses a probabilistic knowledge of a hypothesis before any observation, and then presents an estimated number for the hypothesis after the observations. 
Bayes theory expressed as formula (1):

$$
P(H \mid E) \quad \frac{P(E \mid H) \cdot P(H)}{P(E)}, \quad P(E) \neq 0
$$

The first practical application of BN was the classical problem of medical diagnosis (Patterson, Eng, Horowitz, Gorlin, \& Goldstein, 1984). Companies like Microsoft used these networks for fault diagnosis, specially printer troubleshooting (Heckerman, Mamdani, \& Wellman, 1995). The predictive and diagnostic abilities of BN's make it a powerful tool for decision making under uncertainty. In recent years using of BNs has increased and various applications were created, but its application in SCRM is a new problem that we are going to discuss it.

\subsection{Modeling}

The best model will be attained when a balance occurs between competencies and weaknesses of a model (Pitchforth \& Mengersen, 2013). In order to define this balance, supply chain managers should decide based on their needs and situations. After defining objectives in real world, we can identify important issues and risks. Accuracy and number of variables have essential roles in model validation, because few numbers of variables cannot cover all parts of the problem and on the other hand more number of variables can disrupt effectiveness of model (Gunasekaran et al., 2004). There exist a lot of tools for determining risk. The most common method is Failure Method and Event Analysis (FMEA) which was developed by NASA in 1963. In this method a number between one and ten was assigned for severity and occurring probability of each variable, so that bigger numbers show more criticality and importance. In this paper we used Failure Method and Event Criticality Analysis (FMECA) that has diagnostic and control factor in addition to severity and probability. The number of diagnose and control factor were vice versa and assigned from 10 to 1 , so that smaller numbers show the efficiency of control mechanism. Risk ranking is based on 3 parameters and calculated using formula (2):

$$
\mathrm{RPN}_{\mathrm{i}}=\mathrm{S}_{\mathrm{i}} \times \mathrm{O}_{\mathrm{i}} \times \mathrm{D}_{\mathrm{i}} \quad \forall \mathrm{i}
$$

The bigger the number, the more critical is the factor. After literature review and case survey, by considering SCOR metrics, several brainstorming sessions held with experts and 23 performance metrics determined in 5 groups (Attributes of SCOR). Then some of metrics which their RPN were bigger than 100 were selected as a base model for performance metrics. The goal is to prepare a flexible model that is representative of real statue.

Expert opinion can be elicited to create a Bayesian Belief Network. A common technique for validating $\mathrm{BNs}$ based on expert opinion in the absence of complete data, is simply asking the 
experts whether they agree with the model structure, discretization, and parameterization or not (Pitchforth \& Mengersen, 2013).

The common cause for customer facing nodes is considered as a 'ranked' variable with three levels: low, Medium, and high. In this study, the new systematic approach in determining the probabilities of a BN, proposed by Chin, Tang, Yang, Wong and Wang (2009) is used.

Imagine a case that there are $\mathrm{n}$ states $S_{1}, S_{2}, \ldots, S_{N}$ of a prior node $N$, and we should identify the probability of each state $S_{i}$, i.e., $P\left(S_{i}\right)$. Usually, $P\left(S_{i}\right)$ is specified directly by experts opinion which derived from their knowledge and experience, but this became so difficult when we have several number of states.

Using pair-wise comparisons between states for specifying their probabilities is another way for this aim. In this approach, the prior probability of each state of a node can be determined by the following pair-wise comparison matrix:

\begin{tabular}{|c|c|c|c|c|c|}
\hline & $\mathbf{S}_{1}$ & $\mathbf{S}_{2}$ & $\ldots$ & $\mathbf{S}_{\mathbf{n}}$ & $\boldsymbol{\omega}$ \\
\hline $\mathrm{S}_{1}$ & $\mathrm{a}_{11}$ & $\mathrm{a}_{12}$ & $\ldots$ & $\mathrm{a}_{1 \mathrm{n}}$ & $\omega_{1}$ \\
\hline $\mathrm{S}_{2}$ & $\mathrm{a}_{21}$ & $\mathrm{a}_{22}$ & $\ldots$ & $\mathrm{a}_{2 \mathrm{n}}$ & $\omega_{2}$ \\
\hline$\ldots$ & $\ldots$ & $\ldots$ & $\ldots$ & $\ldots$ & $\ldots$ \\
\hline $\mathrm{S}_{\mathrm{n}}$ & $\mathrm{a}_{\mathrm{n} 1}$ & $\mathrm{a}_{\mathrm{n} 1}$ & $\ldots$ & $\mathrm{a}_{\mathrm{nn}}$ & $\omega_{\mathrm{n}}$ \\
\hline
\end{tabular}

Table 1. pair-wise comparison matrix for prior nodes probability

$a_{i j}$ means "which one is more likely to occur and how much more likely?" and the value of $a_{i j}$ represents the multiple of the likelihood of the presence of $S_{i}$ over that of $S_{j}$. Obviously $a_{j i}=1 / a_{i j}$ and $a_{i i}=1$, so there are $\mathrm{n}(\mathrm{n}-1)$ different comparisons in the above pair-wise comparison matrix. However, it is sufficient to provide $n(n-1)$ interrelated comparisons rather than all the $n(n-1)$ different comparisons, although it is useful to have more comparisons for checking consistency (Khodakarami \& Abdi, 2014).

When we have consistency in decision making, we can simply calculate wi by equation formula (3):

$$
\mathrm{Wi}=\frac{a_{i}}{\sum a_{i j}}
$$


In the case that we do not have complete consistency least square method will be better than "Eigen value" of Saaty. This method tries to minimize the difference between $a_{i j}$ and $W_{i} / W_{j}$ due to the inconsistency in decision maker decisions. So we should minimize model (4):

$$
\operatorname{Min}: \sum \sum\left(a_{i j} \cdot w_{j}-w_{i}\right)^{2} \quad \text { s.t: } \sum w_{i}=1, w_{i}>0
$$

The SCOR model defines two types of performance attributes (SCOR, 2006). The customerfacing performance attributes which take reliability, responsiveness, and flexibility into account and the internal-facing attributes which includes cost and assets. It is important to note that, since the customer facing nodes were qualitative, distributions of them considered Rank with three states (Low, Medium, High). Also each child node constituted of the parent nodes with a special weight. The natures of internal facing nodes are quantitative and we estimated their distribution from historical data. All of these nodes have Normal distribution with their special mean and variance. Also child nodes are weighted mean of their parents with Normal distributions. Final node has conditional value and it was considered partitioned expression based on its parents value. We have special distribution for each of the customer facing states. It has T-normal distribution and it was ranged between 0 and 1 . The more this index is, the better its performance will be and vice versa. The nodes will be discussed in 4.2.1 to 4.2.5 sections.

\subsubsection{Reliability}

Reliability in supply chain has essential effect on customer satisfaction and SCP. Reliability is the percentage of orders meeting delivery performance with complete and accurate documentation and no delivery damage (Hwang, Lin, \& Lyu, 2008).

There are several variables that affect the delivery or non-delivery of products on time and sometimes these variables are also related to upstream supply chain. In case study carried out in this paper, a number of important variables were considered in the supply chain.

Order consistency, order completeness and filling order accuracy are the selected criteria for measuring delivery reliability in this paper.

Order consistency means that there is a minimal variance in promised versus actual delivery. Completeness of order is the percentage of line items which were eventually shipped completely. Filling order accuracy metric provides a good indication of how well every facet of a supply chain are tuned and coordinated to meet customer demand. ("As of May 10, 2014, supply Chain Council listed on its website http://www.supplychain.org")

Finally, three mentioned variables determined the delivery reliability of products statue. 


\subsubsection{Cost}

There is no doubt that one of the most important variables in supply chain is cost. Cost in here means all direct and indirect expenses associated with operating SCOR business across the supply chain (Hwang et al., 2008).

Total cost in here means that the money that we have spent in order to give the production to customers by conserving other options like quality, etc. So, the more this amount of money is low, SCP is better. In this paper, transportation, inventory, warranty and labors cost as most important variables in SCP have been considered.

As we mentioned before, cost node has been evaluated by its parent's nodes. It has Normal distribution and its mean is weighted mean of its parent's nodes.

\subsubsection{Asset Management}

The financial structure of company as a vast and very important issue in many industries has a key role in profitability. Asset is the time it takes for an investment made to flow back into a company after it has spent for raw materials. It Measures the return an organization receives on its invested capital in supply chain fixed assets. This includes the fixed assets used in plan, source, make, deliver, and Return (Hwang et al., 2008).

Cash to cycle time and inventory days of supply were taken into account as the metrics of the asset management node. An inventory day of supply is defined as total gross value of inventory at standard cost before reserves for excess and obsolescence. The Inventory-Days-of-Supply allows estimating for how long a stock level of a certain material will be sufficient to match upcoming requirements. Cash to cash cycle time is the duration between the purchase of a firm's inventory and the collection of accounts receivable for the sale of that inventory. ("As of May 10, 2014, SAP listed on its website http://wiki.scn.sap.com").

\subsubsection{Flexibility}

The forth factor for measuring SCP goes to the flexibility of company. Flexibility shows the adoption ability of company to the different situations and fluctuations which occurred during the time. In general it means how rapidly a supply chain can effectively respond in near realtime to the customers' needs or when something goes wrong or an opportunity arises. The more a company is flexible, the more it can adopt itself to the situations and deliver the products on time. ("As of May 10, 2014, Supply Chain digest listed on its website http://www.scdigest.com"). 
The ability to meet specific customer service needs, the ability to identify and supply high volumes in a "quick ship" mode, and the ability to plan, source, make and deliver unplanned orders with minimal cost penalties are the considered variables in our model. Function of all the mentioned variables for flexibility are ranked with three states.(Low, Medium, High).

\subsubsection{Responsiveness}

Responsiveness is the average actual cycle time consistently achieved to fulfill customer orders for each individual order. This cycle time starts from the order receipt and ends with customer acceptance of the order (Hwang et al., 2008).

After using FMECA method, length of time to process, produce and ship a received order recognized as the first criteria in this section. The second criteria is the length of promised order cycle (lead) times from order submission to delivery. Like flexibility node, function of all the mentioned variables for responsiveness are ranked with three states. (Low, Medium, High)

The BN model is shown in Figure 1. In this model, the top level, known as determinants, is adopted from the SCOR model by expert team opinion. These are the metrics that company confronted with them in common and naturally they have uncertainty. The second level shows the statue of each of the first level nodes and the third level is helping nodes which are a kind of division (customer facing and internal facing) and also summary of their top level. Supply chain performance showed in forth level.

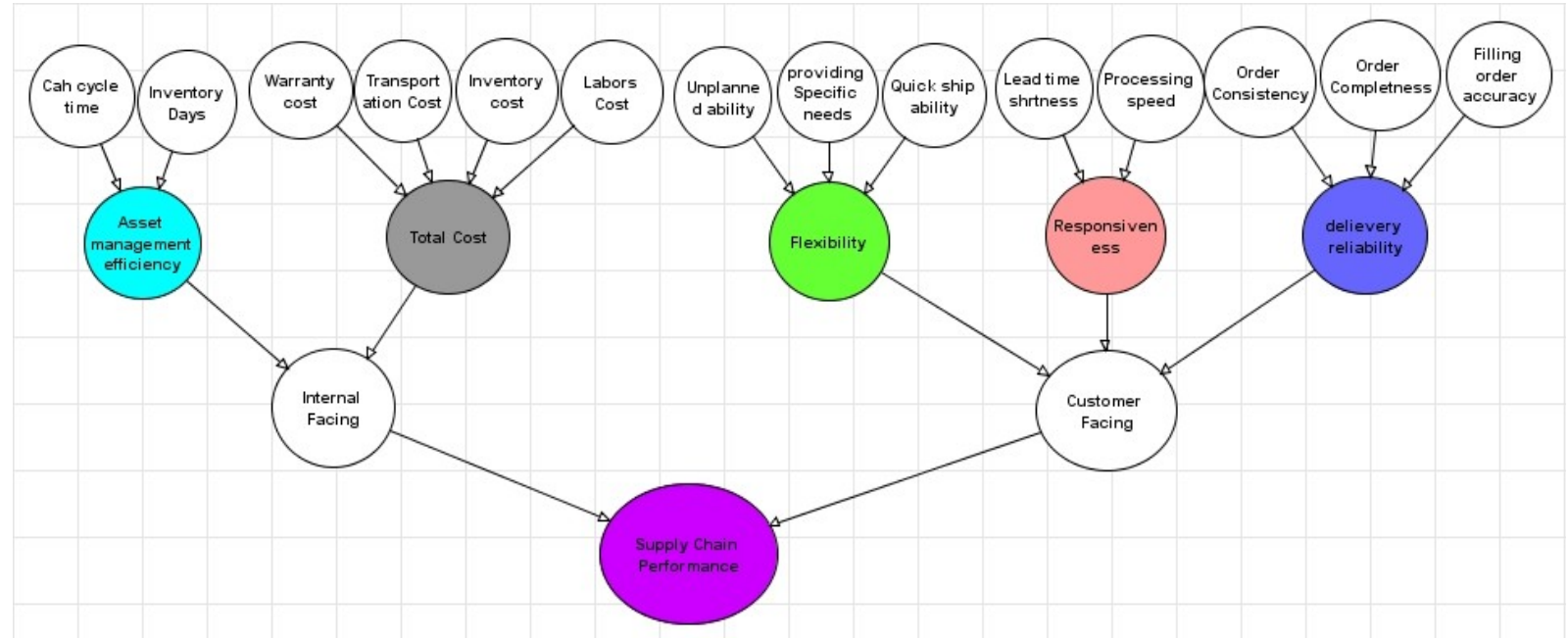

Figure 1 . BN model of supply chain performance 


\section{Model Application}

We evaluated the presented model as a case study in an automobile manufacturing company. According to existing documentation and processes, list of key performance indicators for each section were extracted, compared and adopted to the SCOR metrics. In this research, the Bayesian model has been developed on the basis of a SCOR metrics and a series of discussions with expert team which consisted of academicians and industry personnel. Finally, performance metrics which have uncertainty in their nature were ranked using FMECA.

It is notable that we based our model according to the validation framework suggested by Pitchforth and Mengersen (2013). As we used expert opinions in our model, we should assess its validity in order to be sure about the ability of model to describe the system's mechanism and output. Nomological, face, content, concurrent, convergent, discriminant and predictive validity are seven steps of Pitchforth and Mengersen (2013) proposed for the validation of BNs.

\section{Scenario Analysis}

Basically anything that is not measurable, it is not manageable. The purpose of risk modeling is to get insight into the system performance, represent or express the uncertainties, identify the risk contributors and see the effect of changes. Pollino, Woodberry, Nicholson, Korb and Hart (2007) referred to the concept of sensitivity as a method of testing the predictive validity of expert-elicited networks. Indeed, validation of the mode determines the degree of conformity to reality or the degree of model accuracy. After the validity of the model we can say how reliable it is and how the model outputs can be used in future designs.

For the first scenario analysis, we have considered a scenario in which flexibility criteria are in High state, and other variables are in their default statue. SCP is expected to become better comparing to the base state. As we see in Figure 2, SCP performance has increased to 0.47 . Other variables stayed on their previous values, because the changes will be happened for topbottom variables which are direct connected. We showed just the statue of prior nodes (the first level), because they are the sensible metrics for managers and we can deal about them. All the other child nodes consisted of their parents.

Predictions of probable happenings help the managers and provide them a better view for management of company. In second scenario we want to know the state of prior nodes of customer facing. In what state should the delivery reliability, flexibility and responsiveness parents' nodes be, if we know total cost and asset management efficiency are fixed on their mean value, also we want to increase SCP to 0.6. We expect from prior nodes of customer facing to be better, because SCP has increased to 0.6 , on the other side, internal facing nodes are fixed without any change, therefore; other nodes should compensate this gap. After 
entering observations and running the model, trend of all the prior nodes goes toward High state. For instance, we see that parent nodes of Flexibility changed positively. Processing speed distribution became Low, Medium and High with 6, 38 and 54 percent respectively; as shown in Figure 3. Also Lead time shortness should be High 57 percent and medium 35 percent. Results of this scenario give us worthy information, in a case that we want to increase SCP and also we have constraint in some variables. We can see other changes occurred in prior nodes and compare them with base state in Figure 3.

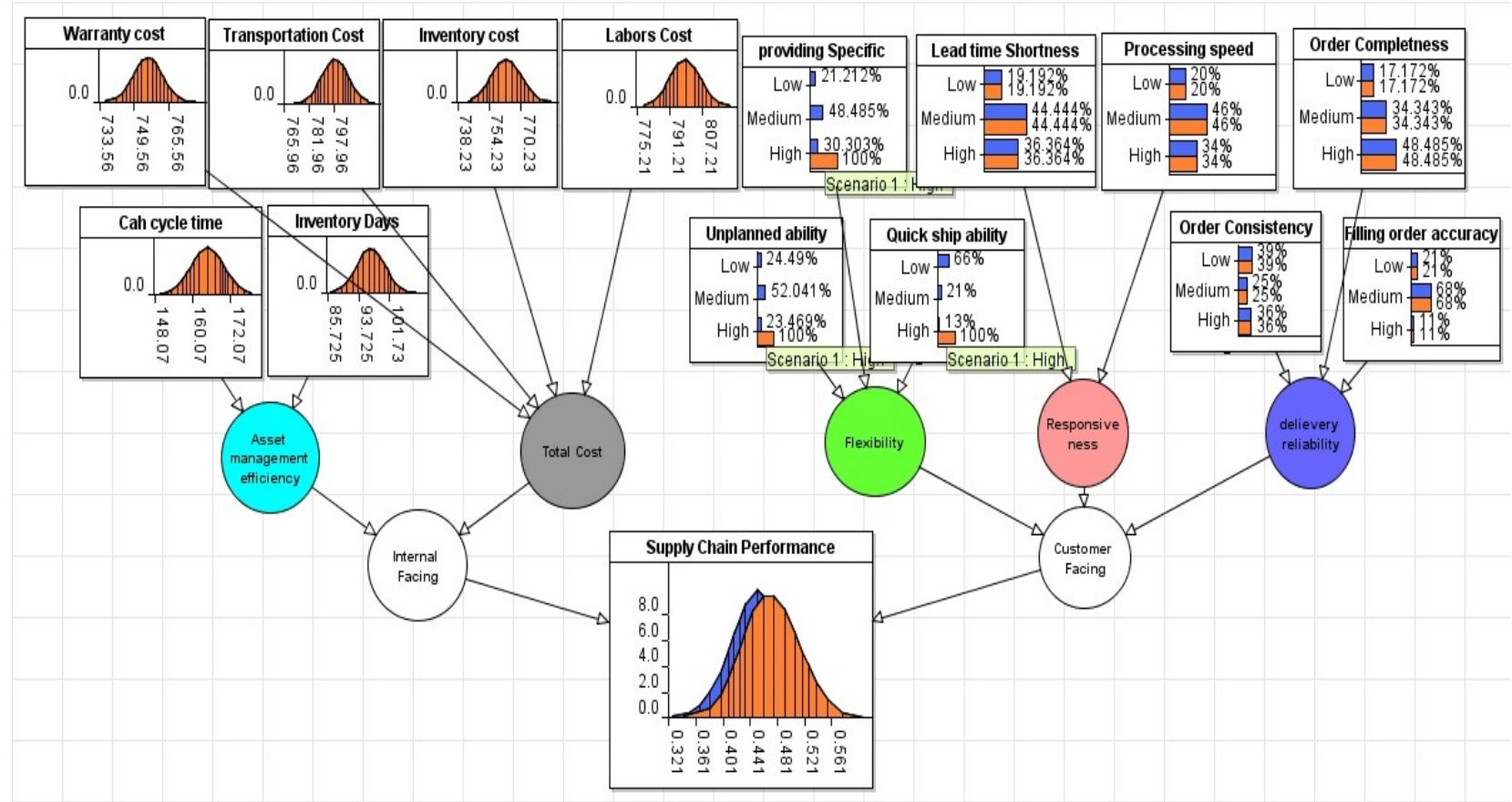

Figure 2. Model statue when Flexibility parents are in High state

Prior nodes which do not have parents are sensible criteria for managers. In fact, managers can make changes in prior nodes based on the predictive and diagnostic results. Figure 4 and Figure 5 provide a ranked tornado graph for sensitivity analysis and their impact on supply chain performance for factors and prior nodes respectively. As we see Total cost is the most important factor for supply chain performance and it can change supply chain performance to 0.4 in Low state and 0.5 in High state. 


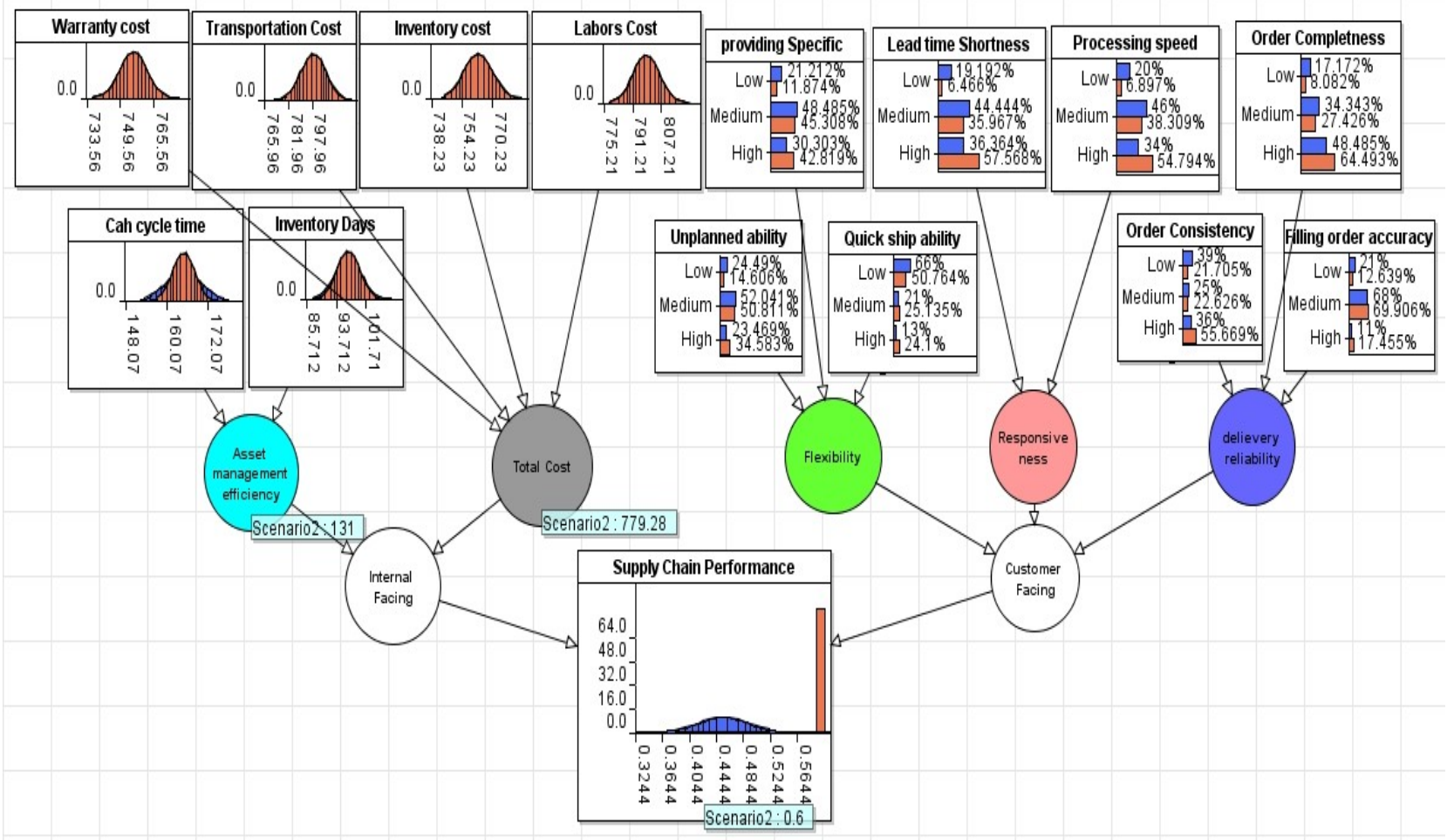

Figure 3. Model statue while running scenario 2

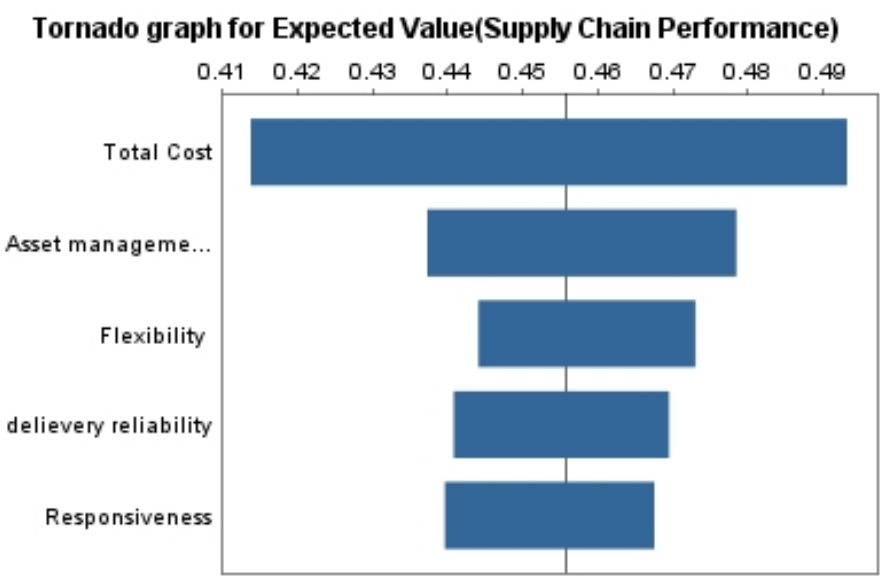

Figure 4. Tornado graph of factors for expected value of supply chain performance

But in prior nodes, Labor cost plays an important role in supply chain performance. It can change supply chain performance between 0.43 and 0.47 . Warranty, Transportation and Inventory costs placed in 2nd, 3rd and 4th places respectively. In this case quick ship ability and unplanned ability have the least impact and importance. We can see detailed information in Figure 5. 


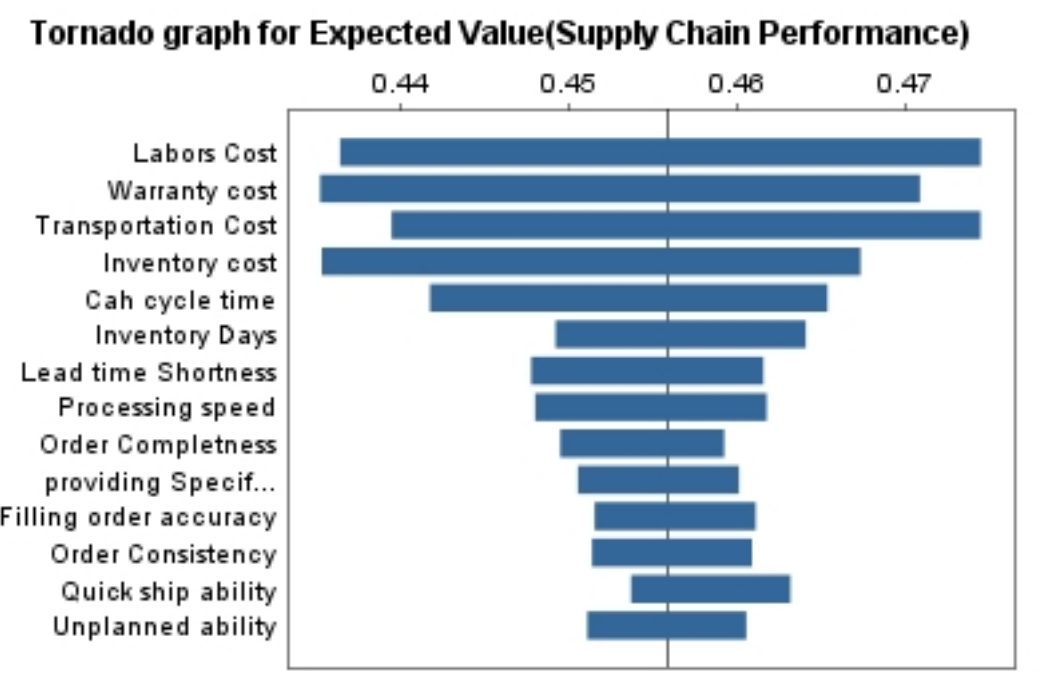

Figure 5. Tornado graph of criteria for expected value of supply chain performance

\section{Conclusion}

The aim of SCRM is to give strategies for reducing negative impacts and enhancing positive effects of risk. Since the shape of the final product delivery is the result of detailed planning in a supply chain, the need for risk management is clear.

In this paper, a Bayesian model for SCRM was presented. By considering SCOR metrics and combining them with principles of BNs, we presented a Bayesian model which has the ability to show SCP. The model is capable of taking into consideration both qualitative and quantitative information. Also the structure of the model has the ability to evaluate potential risks, their impact on SCP and enables proactive decisions. Total cost and its criteria which include costs of labors, warranty, transportation and inventory have the widest range and most effect on supply chain performance, So managing them and controlling their related risk have a vital role for supply chain performance.

However, despite the flexibility of the model and its strengths, it is a prototype model and can be developed from different views. Comparative results obtained from different techniques in real-world problem can help us to obtain a reasonable way to solve the problem. Using simulation and comparing it with the presented model may be a good method for showing their efficiency. 


\section{References}

Adhitya, A., Srinivasan, R., \& Karimi, I.A. (2009). Supply chain risk identification using a HAZOP-based approach. AIChE journal, 55(6), 1447-1463. http://dx.doi.org/10.1002/aic.11764

Arzu Akyuz, G., \& Erman Erkan, T. (2010). Supply chain performance measurement: A literature review. International Journal of Production Research, 48(17), 5137-5155. http://dx.doi.org/10.1080/00207540903089536

Cavinato, J.L. (2004). Supply chain logistics risks: from the back room to the board room. International Journal of Physical Distribution \& Logistics Management, 34(5), 383-387. http://dx.doi.org/10.1108/09600030410545427

Chin, K.-S., Tang, D.-W., Yang, J.-B., Wong, S.Y., \& Wang, H. (2009). Assessing new product development project risk by Bayesian network with a systematic probability generation methodology. Expert Systems with Applications, 36(6), 9879-9890.

http://dx.doi.org/10.1016/j.eswa.2009.02.019

Chopra, S., \& Sodhi, M.S. (2012). Managing risk to avoid supply-chain breakdown. MIT Sloan Management Review (Fall 2004).

Christopher, M., Mena, C., Khan, O., \& Yurt, O. (2011). Approaches to managing global sourcing risk. Supply Chain Management: An International Journal, 16(2), 67-81. http://dx.doi.org/10.1108/13598541111115338

Christopher, M., \& Peck, H. (2004). Building the resilient supply chain. The International Journal of Logistics Management, 15(2), 1-14. http://dx.doi.org/10.1108/09574090410700275

Cirtita, H., \& Glaser-Segura, D.A. (2012). Measuring downstream supply chain performance. Journal of Manufacturing Technology Management, 23(3), 299-314.

http://dx.doi.org/10.1108/17410381211217380

Faisal, M., Banwet, D., \& Shankar, R. (2007). Management of risk in supply chains: SCOR approach and analytic network process. Paper presented at the Supply Chain Forum: An International Journal.

Fox, M.S., Barbuceanu, M., \& Teigen, R. (2001). Agent-oriented supply-chain management Information-Based Manufacturing, 81-104, Springer.

Giunipero, L.C., \& Eltantawy, R.A. (2004). Securing the upstream supply chain: a risk management approach. International Journal of Physical Distribution \& Logistics Management, 34(9), 698-713. http://dx.doi.org/10.1108/09600030410567478

Gunasekaran, A., Patel, C., \& McGaughey, R.E. (2004). A framework for supply chain performance measurement. International journal of production economics, 87(3), 333-347. http://dx.doi.org/10.1016/j.ijpe.2003.08.003 
Gunasekaran, A., Patel, C., \& Tirtiroglu, E. (2001). Performance measures and metrics in a supply chain environment. International journal of operations \& production Management, 21(1/2), 71-87. http://dx.doi.org/10.1108/01443570110358468

Hallikas, J., Karvonen, I., Pulkkinen, U., Virolainen, V.M., \& Tuominen, M. (2004). Risk management processes in supplier networks. International Journal of Production Economics, 90(1), 47-58. http://dx.doi.org/10.1016/j.ijpe.2004.02.007

Heckerman, D., Mamdani, A., \& Wellman, M.P. (1995). Real-world applications of Bayesian networks. Communications of the ACM, 38(3), 24-26. http://dx.doi.org/10.1145/203330.203334

Hendricks, K.B., \& Singhal, V.R. (2005). Association between supply chain glitches and operating performance. Management science, 51(5), 695-711.

http://dx.doi.org/10.1287/mnsc.1040.0353

Hendricks, K.B., Singhal, V.R., \& Zhang, R. (2009). The effect of operational slack, diversification, and vertical relatedness on the stock market reaction to supply chain disruptions. Journal of Operations Management, 27(3), 233-246.

http://dx.doi.org/10.1016/j.jom.2008.09.001

Hunter, L.M., Kasouf, C.J., Celuch, K.G., \& Curry, K.A. (2004). A classification of business-to-business buying decisions: risk importance and probability as a framework for e-business benefits. Industrial marketing management, 33(2), 145-154.

http://dx.doi.org/10.1016/S0019-8501(03)00058-0

Hwang, Y.-D., Lin, Y.-C., \& Lyu Jr, J. (2008). The performance evaluation of SCOR sourcing process-The case study of Taiwan's TFT-LCD industry. International journal of production economics, 115(2), 411-423. http://dx.doi.org/10.1016/j.ijpe.2007.09.014

Johnson, M.E., \& Pyke, D.F. (2000). A framework for teaching supply chain management. Production and Operations Management, 9(1), 2-18. http://dx.doi.org/10.1111/j.1937-5956.2000.tb00319.x

Jüttner, U., Peck, H., \& Christopher, M. (2003). Supply chain risk management: outlining an agenda for future research. International Journal of Logistics: Research and Applications, 6(4), 197-210. http://dx.doi.org/10.1080/13675560310001627016

Khodakarami, V., \& Abdi, A. (2014). Project cost risk analysis: A Bayesian networks approach for modeling dependencies between cost items. International Journal of Project Management (0). http://dx.doi.org/10.1016/j.ijproman.2014.01.001

Lambert, D.M., \& Pohlen, T.L. (2001). Supply chain metrics. The International Journal of Logistics Management, 12(1), 1-19. http://dx.doi.org/10.1108/09574090110806190

Li, X., \& Barnes, I. (2008). Proactive supply risk management methods for building a robust supply selection process when sourcing from emerging markets. Strategic Outsourcing: An International Journal, 1(3), 252-267. http://dx.doi.org/10.1108/17538290810915308 
Lockamy, A., \& McCormack, K. (2004). Linking SCOR planning practices to supply chain performance: An exploratory study. International Journal of Operations \& Production Management, 24(12), 1192-1218. http://dx.doi.org/10.1108/01443570410569010

Manuj, I., \& Mentzer, J.T. (2008). Global supply chain risk management strategies. International Journal of Physical Distribution \& Logistics Management, 38(3), 192-223. http://dx.doi.org/10.1108/09600030810866986

McCormack, K., Wilkerson, T., Marrow, D., Davey, M., Shah, M., \& Yee, D. (2008). Managing risk in your organization with the SCOR methodology. The Supply Chain Council Risk Research Team.

MCCREA, B. (2006). Metrics take center stage. Logistics Management, 37(1).

Milgate, M. (2001). Supply chain complexity and delivery performance: an international exploratory study. Supply Chain Management: An International Journal, 6(3), 106-118. http://dx.doi.org/10.1108/13598540110399110

Min, H., \& Zhou, G. (2002). Supply chain modeling: past, present and future. Computers \& Industrial Engineering, 43(1), 231-249. http://dx.doi.org/10.1016/S0360-8352(02)00066-9

Norrman, A., \& Jansson, U. (2004). Ericsson's proactive supply chain risk management approach after a serious sub-supplier accident. International Journal of Physical Distribution \& Logistics Management, 34(5), 434-456. http://dx.doi.org/10.1108/09600030410545463

Pai, R.R., Kallepalli, V.R., Caudill, R.J., \& Zhou, M. (2003). Methods toward supply chain risk analysis. Paper presented at the Systems, Man and Cybernetics, 2003. IEEE International Conference on. http://dx.doi.org/10.1109/ICSMC.2003.1245702

Patterson, R.E., Eng, C., Horowitz, S.F., Gorlin, R., \& Goldstein, S.R. (1984). Bayesian comparison of cost-effectiveness of different clinical approaches to diagnose coronary artery disease. Journal of the American College of Cardiology, 4(2), 278-289.

http://dx.doi.org/10.1016/S0735-1097(84)80214-4

Pettit, T.J., Fiksel, J., \& Croxton, K.L. (2010). Ensuring supply chain resilience: Development of a conceptual framework. Journal of Business Logistics, 31(1), 1-21.

http://dx.doi.org/10.1002/j.2158-1592.2010.tb00125.x

Pitchforth, J., \& Mengersen, K. (2013). A proposed validation framework for expert elicited Bayesian Networks. Expert Systems with Applications, 40(1), 162-167.

http://dx.doi.org/10.1016/j.eswa.2012.07.026

Pollino, C.A., Woodberry, O., Nicholson, A., Korb, K., \& Hart, B.T. (2007). Parameterisation and evaluation of a Bayesian network for use in an ecological risk assessment. Environmental Modelling \& Software, 22(8), 1140-1152. http://dx.doi.org/10.1016/j.envsoft.2006.03.006

Rabelo, L., Eskandari, H., Shaalan, T., \& Helal, M. (2007). Value chain analysis using hybrid simulation and AHP. International Journal of Production Economics, 105(2), 536-547. http://dx.doi.org/10.1016/j.ijpe.2006.05.011 
Rowbottom, U. (2004). Managing risk in global supply chains. Supply Chain Practice, 6(2), 16-23.

SCOR (2006). Available at: www.scor.com

Shi, D. (2004). A review of enterprise supply chain risk management. Journal of systems science and systems engineering, 13(2), 219-244. http://dx.doi.org/10.1007/s11518-006-0162-2

Svensson, G. (2000). A conceptual framework for the analysis of vulnerability in supply chains. International Journal of Physical Distribution \& Logistics Management, 30(9), 731-750. http://dx.doi.org/10.1108/09600030010351444

Tang, C., \& Tomlin, B. (2008). The power of flexibility for mitigating supply chain risks. International Journal of Production Economics, 116(1), 12-27. http://dx.doi.org/10.1016/j.ijpe.2008.07.008

Tang, C. S. (2006). Perspectives in supply chain risk management. International journal of production economics, 103(2), 451-488. http://dx.doi.org/10.1016/j.ijpe.2005.12.006

Tuncel, G., \& Alpan, G. (2010). Risk assessment and management for supply chain networks: A case study. Computers in industry, 61(3), 250-259. http://dx.doi.org/10.1016/j.compind.2009.09.008

Van Hoek, R. (2003). Are you ready? Risk readiness tactics for the supply chain. Logistics Research Network.

Wagner, S.M., \& Bode, C. (2006). An empirical investigation into supply chain vulnerability. Journal of purchasing and supply management, 12(6), 301-312. http://dx.doi.org/10.1016/j.pursup.2007.01.004

Wagner, S.M., \& Neshat, N. (2010). Assessing the vulnerability of supply chains using graph theory. International journal of production economics, 126(1), 121-129.

http://dx.doi.org/10.1016/j.ijpe.2009.10.007

Wu, D., \& Olson, D.L. (2008). Supply chain risk, simulation, and vendor selection. International Journal of Production Economics, 114(2), 646-655.

http://dx.doi.org/10.1016/j.ijpe.2008.02.013

Wu, T., Blackhurst, J., \& Chidambaram, V. (2006). A model for inbound supply risk analysis. Computers in industry, 57(4), 350-365. http://dx.doi.org/10.1016/j.compind.2005.11.001

Yan, H., Xu, B., \& Wang, C. (2008). Study on the Optimization Measures of Reducing Supply Chain Cooperation Risks. Paper presented at the Information Processing (ISIP), 2008 International Symposiums on. http://dx.doi.org/10.1109/ISIP.2008.16

Yongsheng, L., \& Kun, Z. (2009). Study on Evaluation Index System for Supply Chain Risk. Proceeding of the 2009 First International Conference on Information Science and Engineering, pp. 4510-4513. 


\section{Appendix}

\begin{tabular}{|c|c|c|c|c|c|c|c|c|}
\hline Entity & $\begin{array}{l}\text { Potential } \\
\text { failure }\end{array}$ & Potential effect & Severity & $\begin{array}{l}\text { Potential } \\
\text { causes of } \\
\text { failure }\end{array}$ & Occurrence & $\begin{array}{l}\text { Detection/ } \\
\text { current } \\
\text { control }\end{array}$ & $\begin{array}{l}\text { Detection } \\
\text { score }\end{array}$ & RPN \\
\hline \multirow{5}{*}{ Reliability } & $\begin{array}{l}\text { Decline in } \\
\text { business relation }\end{array}$ & $\begin{array}{l}\text { Customer } \\
\text { unsatisfaction }\end{array}$ & 7 & $\begin{array}{l}\text { Order } \\
\text { completeness }\end{array}$ & 4 & R\&D activities & 4 & 112 \\
\hline & $\begin{array}{l}\text { Lack of } \\
\text { transportation } \\
\text { capacity }\end{array}$ & Delay in delivery & 6 & $\begin{array}{l}\text { Percentage of } \\
\text { order in first } \\
\text { shipment }\end{array}$ & 2 & $\begin{array}{l}\text { Alternative } \\
\text { vehicles }\end{array}$ & 5 & 60 \\
\hline & $\begin{array}{l}\text { Defected } \\
\text { products }\end{array}$ & $\begin{array}{l}\text { Increase of } \\
\text { inspection cost \& } \\
\text { Reputation risk }\end{array}$ & 6 & $\begin{array}{l}\text { Order } \\
\text { consistency }\end{array}$ & 5 & $\begin{array}{l}\text { Statistical } \\
\text { quality control, } \\
\text { Inspection }\end{array}$ & 4 & 120 \\
\hline & $\begin{array}{l}\text { transporting } \\
\text { delay }\end{array}$ & $\begin{array}{l}\text { Customer } \\
\text { unsatisfaction }\end{array}$ & 7 & $\begin{array}{l}\text { On time } \\
\text { shipment }\end{array}$ & 2 & $\begin{array}{l}\text { Proper } \\
\text { Scheduling }\end{array}$ & 5 & 90 \\
\hline & $\begin{array}{l}\text { Lack of raw } \\
\text { material }\end{array}$ & Delay in delivery & 6 & Order fitness & 6 & $\begin{array}{l}\text { Alternative } \\
\text { suppliers }\end{array}$ & 4 & 144 \\
\hline \multirow{4}{*}{ Flexibility } & $\begin{array}{l}\text { Loosing } \\
\text { competitive } \\
\text { ability }\end{array}$ & Losing customer & 8 & $\begin{array}{l}\text { Ability to provide } \\
\text { specific needs }\end{array}$ & 3 & $R \& D$ activities & 7 & 166 \\
\hline & \begin{tabular}{|l|} 
Lack of \\
experienced \\
Human resource
\end{tabular} & Reputation risk & 7 & $\begin{array}{l}\text { Emergency } \\
\text { planning }\end{array}$ & 3 & Personal training & 4 & 84 \\
\hline & $\begin{array}{l}\text { Bureaucracy of } \\
\text { company }\end{array}$ & Delay costs & 5 & shipment speed & 5 & $\begin{array}{l}\text { Analyzing } \\
\text { System }\end{array}$ & 5 & 125 \\
\hline & $\begin{array}{l}\text { Lack of } \\
\text { equipment }\end{array}$ & Delivery delay & 5 & $\begin{array}{l}\text { Increase in } \\
\text { unplanned } \\
\text { planning }\end{array}$ & 3 & $\begin{array}{l}\text { Buying modern } \\
\text { equipment }\end{array}$ & 3 & 216 \\
\hline \multirow{3}{*}{ Responsiveness } & $\begin{array}{l}\text { Slowness for } \\
\text { changing }\end{array}$ & Lost Profit & 6 & $\begin{array}{l}\text { Lead time } \\
\text { Shortness }\end{array}$ & 6 & $\begin{array}{l}\text { Risk Sharing, } \\
\text { Risk taking }\end{array}$ & 6 & 216 \\
\hline & $\begin{array}{l}\text { Technical } \\
\text { problems }\end{array}$ & Unfaithful & 7 & Processing time & 4 & Scheduling, TPM & 5 & 140 \\
\hline & $\begin{array}{l}\text { Demand } \\
\text { increase }\end{array}$ & Unsatisfaction & 5 & Speed decrease & 4 & Forecasting & 4 & 80 \\
\hline \multirow{6}{*}{ Cost } & Inflation & Price increase & 3 & $\begin{array}{l}\text { Transportation } \\
\text { cost }\end{array}$ & 5 & \begin{tabular}{|l|} 
Improving \\
infrastructure, \\
Insurance
\end{tabular} & 6 & 90 \\
\hline & Overhead costs & Profit decline & 4 & $\begin{array}{l}\text { Bureaucracy } \\
\text { costs }\end{array}$ & 3 & $\begin{array}{l}\text { Analyzing } \\
\text { System }\end{array}$ & 5 & 60 \\
\hline & \begin{tabular}{|l|} 
Regulation and \\
political \\
problems \\
\end{tabular} & Losing customer & 7 & Labors cost & 6 & Insurance & 6 & 252 \\
\hline & Quality costs & $\begin{array}{l}\text { Increase in } \\
\text { productions price }\end{array}$ & 4 & Warranty cost & 6 & $\begin{array}{l}\text { Statistical } \\
\text { quality control }\end{array}$ & 6 & 144 \\
\hline & Human error & Profit decline & 4 & $\begin{array}{l}\text { Cost of order } \\
\text { management }\end{array}$ & 4 & Personal training & 7 & 112 \\
\hline & $\begin{array}{l}\text { Increase in } \\
\text { exchange rate }\end{array}$ & $\begin{array}{l}\text { Goods } \\
\text { expensiveness }\end{array}$ & 4 & Inventory cost & 6 & $\begin{array}{l}\text { Investing in } \\
\text { different } \\
\text { sections }\end{array}$ & 8 & 192 \\
\hline \multirow{5}{*}{$\begin{array}{l}\text { Asset } \\
\text { management }\end{array}$} & Overhead costs & Profit decline & 4 & Gross margin & 4 & $\begin{array}{l}\text { Analyzing } \\
\text { System }\end{array}$ & 5 & 80 \\
\hline & Slow production & Profit decline & 4 & Cash cycle time & 6 & \begin{tabular}{|l|} 
Human Training, \\
Analyzing \\
System
\end{tabular} & 5 & 120 \\
\hline & Slow production & Untrusting & 6 & Asset turn & 3 & Scheduling & 5 & 90 \\
\hline & Inflation & Bankruptcy & 4 & $\begin{array}{l}\text { Operation } \\
\text { Income }\end{array}$ & 5 & Insurance & 6 & 120 \\
\hline & $\begin{array}{l}\text { Increase in } \\
\text { production cost }\end{array}$ & Price increase & 5 & $\begin{array}{l}\text { Earnings per } \\
\text { share }\end{array}$ & 4 & Forecasting & 4 & 80 \\
\hline
\end{tabular}

Table 2. Application of the FMECA to the supply chain performance

Journal of Industrial Engineering and Management, 2015 (www.jiem.org)

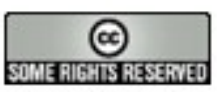

Article's contents are provided on a Attribution-Non Commercial 3.0 Creative commons license. Readers are allowed to copy, distribute and communicate article's contents, provided the author's and Journal of Industrial Engineering and Management's names are included.

It must not be used for commercial purposes. To see the complete license contents, please visit

http://creativecommons.org/licenses/by-nc/3.0/. 